\title{
Prevalence of Cardiovascular Risk Factors among Group ' $C$ ' Employees of a Public Health Institute in Delhi, India
}

\author{
Dr. Rabi Bhushan ${ }^{1}$, Dr. Shikha Nargotra ${ }^{2 *}$, Dr. Nanthini Subbiah ${ }^{3}$
}

\author{
${ }^{1}$ Tutor, Department of Preventive and Social Medicine, SNM Medical College, Dhanbad, Jharkhand, India \\ ${ }^{2}$ PGDPHM, NIHFW, New Delhi, India \\ ${ }^{3}$ Professor, Department of Community Health Administration, NIHFW, New Delhi, India
}

DOI: $10.36347 /$ sjams.2020.v08i12.028

| Received: 15.12.2020 | Accepted: 23.12.2020 | Published: 26.12.2020

*Corresponding author: Dr. Shikha Nargotra

Abstract

Original Research Article

Introduction: Cardiovascular disease (CVD) is a class of disease that involves heart or blood vessels. A risk factor is any attribute, characteristic or exposure of an individual that increases the likelihood of developing disease or injury. The WHO has prioritized the following risk factors for CVD: - Tobacco use, Alcohol consumption, Hypertension, Physical inactivity, Unhealthy diet and Obesity. If appropriate action is taken to control or reduce these risk factors, the onset of CVDs can be prevented or delayed. Material and Methods: A descriptive cross-sectional research study was conducted using interview schedule (modified WHO STEPS instrument) to gather data from the Group ' $\mathrm{C}$ ' employees working in The National Institute of Health and Family Welfare, New Delhi. The information regarding the various risk factors related to the cardiovascular disease was collected and analysed using MS excel and SPSS version 20 software. Result and Conclusion: The findings revealed that almost all of the risk factors are present in study population. Physical inactivity $(62 \%)$ was the commonest cardiovascular risk factor followed by tobacco use $(54.5 \%)$. Almost all of the behavioural risk factors were started in adolescence or in young age. Based on the findings, it is recommended that screening at the time of joining the job and thereafter, frequent health education and health promotion activities should be imparted.

Keywords: Risk factor, Cardiovascular disease, Hypertension, Body Mass Index (BMI), Abdominal obesity.

Copyright $\left({ }^{\circ} 2020\right.$ The Author(s): This is an open-access article distributed under the terms of the Creative Commons Attribution 4.0 International License (CC BY-NC 4.0) which permits unrestricted use, distribution, and reproduction in any medium for non-commercial use provided the original author and source are credited.

\section{INTRODUCTION}

Cardiovascular disease (CVD) is a class of disease that involves heart or blood vessels. CVD includes coronary heart disease, such as angina and Myocardial infarction (Commonly known as Heart attack), and other diseases including stroke, heart failure, cardiomyopathy, arrhythmia, valvular heart disease, carditis, peripheral vascular disease and venous thrombosis. It is one of the four main types of noncommunicable diseases (NCDs) which include cancer, chronic lung disease and diabetes mellitus, in addition to cardio vascular disease.

An NCD is a medical condition or disease that is by definition non-infectious and non-transmissible among people. These include diseases which are chronic, evolve slowly and progress relentlessly. Globally, the disease pattern is shifting from communicable to non-communicable disease and they are the major cause of morbidity and mortality. Latest estimate from Global burden of disease study (GBD) says that total number of deaths from noncommunicable disease have increased by $14.1 \%$ in
2015. NCD kills 40 million people each year, equivalent to $70 \%$ of all deaths globally. NCDs contribute to around 5.87 million deaths that account for $60 \%$ of all deaths in India. India shares more than two-third of the total deaths due to NCDs in the SouthEast Asia Region (SEAR) of WHO [1].

The recent reports of 3 large prospective studies from India suggest a higher proportion of mortality attributable to CVD (30\%-40\%). Ischemic heart disease (IHD) and stroke constitutes the majority of CVD mortality in India (83\%), with IHD being predominant one. Together, IHD and stroke are responsible for more than one-fifth $(21.1 \%)$ of all deaths and one-tenth of the years of life lost in India. The number of years of life lost attributable to CVD has increased by $59 \%$ from 1990 to 2010 (23.2 million to 37 million). CVDs have assumed epidemic proportions in India as well [2].

Hypertensive heart disease, among other CVDs, is a significant problem in India, with an increase of $138 \%$ between the period from 1990 to 2013 [3]. Rheumatic heart disease also continues to be a 
problem in several parts of India, with an estimated 88674 deaths (7 per 100000 population) in the year 2010 [4]. The available estimates suggests that rheumatic heart disease prevalence is in range of 1.5 to 2 per 1000 individuals (2-2.5million cases in absolute number) [5]. The prevalence of NCDs in India is Hypertension 159.46, Diabetes 62.47, Ischemic Heart disease 37 , stroke 1.54 per 1000 population (ICMR) [6].

A risk factor is any attribute, characteristic or exposure of an individual that increases the likelihood of developing disease or injury. It is defined as an aspect of personal behaviour or lifestyle, an environmental exposure, or a hereditary characteristic that is associated with an increase in the occurrence of particular disease, injury or other health condition. These risk factors may be modifiable or nonmodifiable. The WHO has prioritized the following modifiable risk factors for CVD: - Tobacco use (smokeless and smoking), Alcohol consumption, Hypertension, Physical inactivity, Unhealthy diet (increased fat and sodium, with low fruits and vegetable intake) and Obesity [7].

Table-1: Important Cardiovascular risk factors

\begin{tabular}{|l|l|}
\hline Non-modifiable Risk factors & Modifiable Risk factors \\
\hline Age & Tobacco use \\
Gender & Harmful use of Alcohol \\
Ethnicity & Hypertension \\
Family history of CVD & Unhealthy Diet (Dietary Pattern) \\
& Physical Inactivity \\
& Obesity \\
\hline
\end{tabular}

Although morbidity and mortality from CVDs mainly occur in adult hood, exposure to risk factors begins in early life years. If appropriate action is taken to control or reduce these factors, the onset of CVDs can be prevented or delayed. Before instituting any action, it is required that the cardiovascular risk factors in a specific population need to be identified.

The National Institute of Health and Family Welfare (NIHFW), an autonomous organisation under the Ministry of Health and Family welfare, Government of India act as an apex institution as well as think- tank for the promotion of health and family welfare programmes in the country. It conducts regular inservice trainings, workshops and health campaigns on various health themes including non-communicable disease. It is expected that the employees of NIHFW are made aware of healthy habit and behaviour. However, the presence of various cardiovascular risk factors may be commonly prevalent in this population that needs to be identified so that appropriate corrective measures could be recommended. The present study was conducted with the primary objective to identify the presence of risk factors of cardiovascular disease among Group'C' employees of The National institute of Health and Family welfare, New Delhi.

\section{Material And Methods}

The study adopted descriptive cross-sectional research design. The study was conducted at The National institute of health and family welfare, New Delhi (NIHFW) over a period of two months, May 2018 to June 2018 . The study participants were the Group ' $\mathrm{C}$ ' employees of The National institute of Health and Family Welfare, New Delhi. Purposive sampling technique was used to select the study participants. There were total 241 permanent employees working in the NIHFW. Out of which, 140 were Group ' $\mathrm{C}$ ' employees. The Samples for this study were Group " $\mathrm{C}$ " employees between the age group of 30-60 years. The inclusion criteria were the Group " $\mathrm{C}$ " employees falling in the age group of 30-60 years and who gave consent for the study. The employees not falling in the defined age category and who have already been diagnosed with any cardio-vascular disease were excluded from the study. Finally, a sample size of 68 was taken. The data was collected using modified WHO STEPS instrument. Data was collected after explaining the purpose and nature of study and obtaining informed consent from the study participants. Data entry and analysis was done using MS EXCEL 2010 and SPSS version 20 computer software. Ethical approval and Permission for conducting the study was obtained from the Ethics Committee of The National institute of Health and Family Welfare, New Delhi.

\section{ReSULTS}

\section{Demographic Profile of the study participants Age and Sex}

Out of total 68 participants, 26 employees $(38 \%)$ were in the age group 30-35 years, 10 employees $(14.7 \%)$ were in the age group $36-40$ years, 10 employees $(14.7 \%)$ were in the age group 41-50 years whereas $11(16.2 \%)$ employees each from age group of 46-50 and >50 years (Figure-1). The study included 49 males and 19 females. 


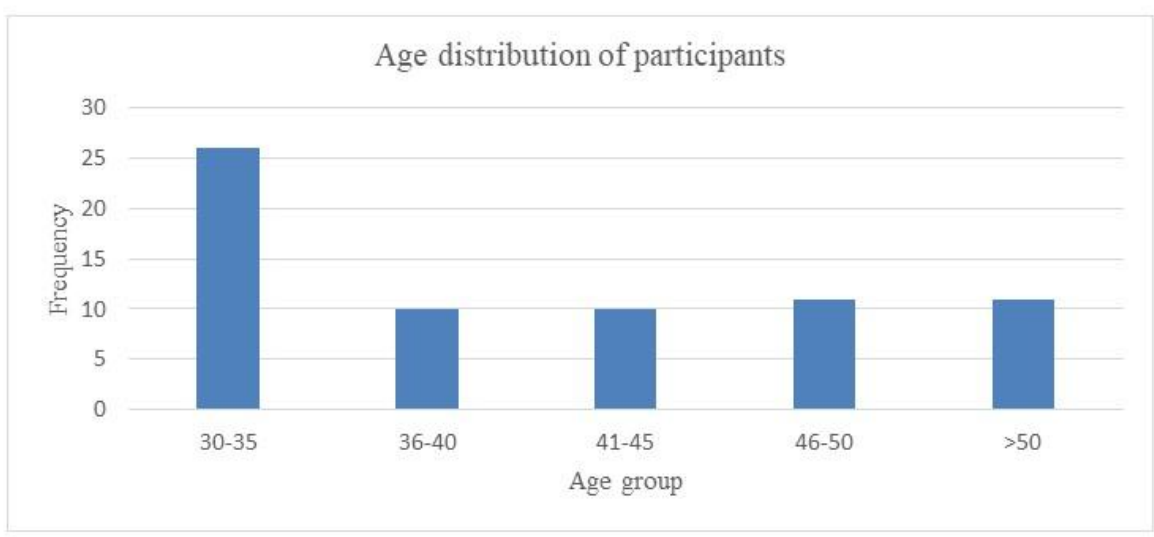

Fig-1: Age distribution of participants

\section{Cardiovascular risk factors \\ Tobacco Use \\ The total of 37 respondents i.e. $54.5 \%$ used tobacco, 31 percent as smoking tobacco and 23.5}

percent as smokeless tobacco (Table-2). No female Participant reported the use of tobacco in any form.

Table-2: Distribution of use of smoking and non-smoking tobacco

\begin{tabular}{|l|l|l|l|l|}
\hline Tobacco Use & \multicolumn{2}{|l|}{ Smoking Tobacco } & \multicolumn{2}{|l|}{ Non- smoking Tobacco } \\
\hline & n & \% & n & \% \\
\hline Yes & 21 & 31 & 16 & 23.5 \\
\hline No & 47 & 69 & 52 & 76.5 \\
\hline Total & 68 & 100 & 68 & 100 \\
\hline
\end{tabular}

\section{Alcohol Consumption}

Out of 68 study participants, 47 percent used to consume alcohol. Rate of alcohol consumption was more among males as compared to females. Among males $28(57 \%)$ were found to use alcohol whereas only $4(21 \%)$ females were found to be using alcohol in this study.

\section{Hypertension}

For the present study, hypertension was defined as Systolic Blood Pressure (SBP) $140 \mathrm{~mm} \mathrm{Hg}$ and above or Diastolic Blood Pressure (DBP) $90 \mathrm{~mm}$ $\mathrm{Hg}$ and above OR Both. The BP was measured using standardized Omron BP machine. In this study, it was found that around $22 \%$ of the study participants were hypertensive (Table-3). Among males hypertension was more common as compared to females.

Table-3: Gender- wise Distribution of Hypertension

\begin{tabular}{|l|l|l|l|l|l|l|}
\hline \multirow{2}{*}{ Hypertension } & \multicolumn{2}{|l|}{ Male } & \multicolumn{2}{l|}{ Female } & \multicolumn{2}{l|}{ Total } \\
\cline { 2 - 7 } & n & \% & n & \% & n & \% \\
\hline No & 36 & 73.4 & 17 & 89.4 & 53 & 77.9 \\
\hline Yes & 13 & 26.6 & 2 & 10.6 & 15 & 22.1 \\
\hline Total & 49 & 100 & 19 & 100 & 68 & 100 \\
\hline
\end{tabular}

\section{Dietary Pattern}

More than half of the respondents (55\%) were non-vegetarian. A good number of study participants (76.5\%) was taking fruits regularly for 3-5 days per week and $81 \%$ were found to take vegetables regularly for more than 5 days per week.

\section{Physical Inactivity}

The American college of Sports Medicine recommends at least 30 minutes of moderate-intensity physical activity of at least 5 days a week [8]. This definition was taken to decide about physical inactivity among participants. Out of the total 68 participants, 62 $\%$ were physically inactive whereas $38 \%$ were found to be involved in doing moderate-intensity physical work regularly (Table-4). Physical inactivity was more common among females as compared to males. 
Table-4: Gender-wise Distribution of Physical Inactivity

\begin{tabular}{|l|l|l|l|}
\hline Physical Inactivity & Male & Female & Total \\
\cline { 2 - 4 } & $\mathbf{N}(\%)$ & $\mathbf{N}(\%)$ & $\mathbf{N}(\%)$ \\
\hline No & $22(45)$ & $4(21)$ & $26(38)$ \\
\hline Yes & $27(55)$ & $15(79)$ & $42(62)$ \\
\hline Total & $49(100)$ & $19(100)$ & $68(100)$ \\
\hline
\end{tabular}

\section{Obesity}

For estimation of obesity, Body Mass Index (BMI) was calculated after taking height and weight measurement of the participants. In addition, Abdominal Obesity was also measured.

\section{Body Mass Index}

In the present study, it was found that more than half $(51.3 \%)$ of the participants were having normal body mass index. 36.7 percent of the participants were overweight while $12 \%$ were obese (Table-4). BMI upto 24.9 was considered as Normal whereas 25.0 to 29.9 was taken as Overweight and BMI 30.0 and above was considered as Obese.

Table-5: Gender-wise distribution of BMI

\begin{tabular}{|l|l|l|l|}
\hline \multirow{2}{*}{ BMI (Body Mass Index) } & Male & Female & Total \\
\cline { 2 - 4 } & $\mathbf{N}(\boldsymbol{\%})$ & $\mathbf{N}(\boldsymbol{\%})$ & $\mathbf{N}(\boldsymbol{\%})$ \\
\hline $18.5-24.9$ (Normal) & $26(53.1)$ & $9(47.5)$ & $35(51.3)$ \\
\hline $25.0-29.9$ (Overweight) & $16(32.6)$ & $9(47.5)$ & $25(36.7)$ \\
\hline 30.0 or more (Obese) & $7(14.3)$ & $1(5)$ & $8(12)$ \\
\hline Total & $49(100)$ & $19(100)$ & $68(100)$ \\
\hline
\end{tabular}

\section{Abdominal Obesity}

The abdominal obesity was measured by determining waist circumference, the upper hip bone and the lower margin of the last palpable rib in the mid axillary line was located and a non-stretchable measuring tape graduated to $1 \mathrm{~mm}$ was placed around the abdomen between the two located points ensuring that the measuring tape is horizontal with the floor and doesn't cause compression on the skin. A measurement of $102 \mathrm{~cm}$ or more for males and $88 \mathrm{~cm}$ or more for females was considered as abdominal obesity respectively.

In the present study, $54.4 \%$ of the participants were having abdominal obesity (Table-5). It was more common among males $(61.2 \%)$ as compared to females $(36.8 \%)$

Table-6: Gender-wise distribution of Abdominal Obesity

\begin{tabular}{|l|l|l|l|l|l|l|}
\hline \multirow{2}{*}{ Abdominal Obesity } & \multicolumn{2}{|l|}{ Male } & \multicolumn{2}{|l|}{ Female } & \multicolumn{2}{|c|}{ Total } \\
\cline { 2 - 8 } & $\mathrm{n}$ & $\%$ & $\mathrm{n}$ & $\%$ & $\mathrm{n}$ & $\%$ \\
\hline No & 19 & 38.8 & 12 & 63.2 & 31 & 45.6 \\
\hline Yes & 30 & 61.2 & 7 & 36.8 & 37 & 54.4 \\
\hline Total & 49 & 100 & 19 & 100 & 68 & 100 \\
\hline
\end{tabular}

\section{DISCUSSION}

The tobacco consumption is one of the major risk factors for the cardiovascular diseases (CVD). The tobacco consumption accounts for $29 \%$ of cardiovascular deaths. In India, tobacco consumption is mainly in two forms: Smokeless tobacco and smoked tobacco. Most commonly used smokeless tobacco products include- tobacco pan masala, tobacco with lime and tobacco with pan and betel nut whereas smoked tobacco products include Cigarette, Cigar, Hukkah and Bidi. The present study has revealed that $54 \%$ of the respondents use tobacco either in smoked or in smokeless form and all the tobacco-users were male. $31 \%$ of the participants were found to be smoking which was lesser in comparison to the findings of a study conducted in Kerala, by TN. Sugathan et al., where $40 \%$ of the participants were smokers [9]. The present study shows that $24 \%$ of the respondents use smokeless tobacco. It is similar with the study finding of G. Rajiv et al., where the prevalence of smokeless tobacco consumption was found to be $20 \%$ and the consumption of tobacco was found to be significantly higher in males than in females [10].

The alcohol consumption is another risk factor for CVD. The present study showed that the prevalence of alcohol consumption was $57 \%$ in males and $21 \%$ in females which is relatively higher than the findings of a study done by R. Vijay et al. where the prevalence was found to be $32.1 \%$ and $10.6 \%$ respectively among male and female participants. ${ }^{[11]}$ One possible reason for this higher prevalence may be the different life style and cultural practices among participants in mega cities like Delhi. In general prevalence of heavy episodic drinking is usually higher in males and abstention is 
higher in females and the similar observations were made in the present study also.

Hypertension accounts for an estimated 54 percent of all stoke and 47 percent of all ischemic heart disease events globally. Hypertension increases the risk for a variety of cardiovascular disease, including stroke, coronary artery disease, heart failure and peripheral vascular disease. In the present study $22 \%$ participants were suffering from hypertension. This finding is relatively higher than the study findings of Bauman A et al., in which it was found that among civilian government employees working in the different parts of the country, 17 percent were suffering from hypertension [12].

In the present study, 45 percent of the participants were using vegetarian diet whereas more than three quarter of the participants were consuming fruits and vegetables on a regular basis. This shows that a good dietary pattern is being followed by them. A study conducted by Shridhar K et al., has also shown the beneficial association of vegetarian diet with CVD risk factors as compared to non-vegetarian diet [13].

Physical inactivity is also one of the important risk factors for CVD. Various studies have estimated that $1 / 3$ of the Indian women do not engage in any leisure- time physical activity Similarly, regular exercise may significantly impact coronary heart disease in women, as some coronary risk factors have a stronger predictive value for coronary heart disease in women as compared with men. In present study only $21 \%$ of females were found to be physically active as compared to $45 \%$ of the males. Recent studies have shown that women who exercise regularly are less likely to develop diabetes mellitus; exercise reduces blood pressure and produce improvement in lipid profile [14].

Many studies have proven that the relationship between Obesity, BMI and cardiovascular diseases. The risk is almost same in men and women. Men and women who are overweight and obese experience an increase in risk of incident coronary heart disease whether measured on a continuous or a categorical scale, compared with normal weight individuals. In the present study, it was found that $54.4 \%$ of the participants were having abdominal obesity. Further, it was observed that $46.9 \%$ of the male participants and $52.5 \%$ of the female participants were overweight or obese, based on calculation of BMI. This finding is consistent with the study findings of Gupta et al in which it was found that $46.2 \%$ of men and $50.7 \%$ of women were overweight or obese [15].

\section{CONCLUSION AND RECOMMENDATION}

Many of the behavioural risk factors like smoking, alcohol consumption were present in the study population. Almost all of the behavioural risk factors were started either in adolescence or in young age. Risk factor like abdominal obesity and hypertension were common in the study population. Physical inactivity (62\%) was the commonest cardiovascular risk factor followed by tobacco use $(54.5 \%)$.

Based on the findings of the present study, it is recommended that employees should be screened for the presence of cardiovascular risk factors at the time of joining the services when they are young. Further, they should be screened at regular intervals for cardiovascular risk factors. Health education and health promotion activities should be undertaken and employees should be encouraged to create a healthier environment around them. In addition, strict implementation of honourable Supreme Court order (by banning the carrying of tobacco within the office premises) should be ensured.

\section{Limitations OF THE STUDY}

The study was conducted in a single institute and the sample size was also kept small due to financial and time constraints. This may have affected the study findings. A more robust study design with bigger sample size decided through more appropriate sampling technique may be conducted in the future.

\section{Conflict of interest: None}

\section{REFERENCES}

1. Cardiovascular disease (CVDs) [Internet]. World Health Organization. 2018. [cited 15 May 2020]. Available from: http://www.who.int/newsroom/factsheets/details/cardiovascular-disease(cvds)

2. Patel V, Chatterji S, Chisholm D, Ebrahim S, Gopalakrishna G, Mathers C, Mohan V, Prabhakaran D, Ravindran RD, Reddy KS. Chronic diseases and injuries in India. The Lancet. 2011 Jan 29;377(9763):413-28.

3. Xavier D, Pais P, Devereaux PJ, Xie C, Prabhakaran D, Reddy KS, Gupta R, Joshi P, Kerkar P, Thanikachalam S, Haridas KK. Treatment and outcomes of acute coronary syndromes in India (CREATE): a prospective analysis of registry data. The Lancet. 2008 Apr 26;371(9622):1435-42.

4. Lopez AD, Mathers CD, Ezzati M, Jamison DT, Murray CJ. Global and regional burden of disease and risk factors, 2001: systematic analysis of population health data. The lancet. 2006 May 27;367(9524):1747-57.

5. Ajay VS, Prabhakaran D, Jeemon P, Thankappan KR, Mohan V, Ramakrishnan L, Joshi P, Ahmed FU, Mohan BV, Chaturvedi V, Mukherjee R. Prevalence and determinants of diabetes mellitus in the Indian industrial population. Diabetic medicine. 2008 Oct;25(10):1187-94.

6. World Health Organization. Preventing chronic diseases: a vital investment [Internet][cited 15 
November 2020]. Available from: www.who.int/chp/chronic_disease_report/en.

7. WHO global report 2005 - Preventing chronic diseases: a vital investment. Geneva: World Health Organization; 2005.

8. Pate RR, Pratt M, Blair SN, Haskell WL, Macera CA, Bouchard C, Buchner D, Ettinger W, Heath GW, King AC, Kriska A. Physical activity and public health: a recommendation from the Centers for Disease Control and Prevention and the American College of Sports Medicine. Jama. 1995 Feb 1;273(5):402-7.

9. Sugathan TN, Soman CR, Sankaranarayanan K. Behavioural risk factors for non communicable diseases among adults in Kerala, India. Indian Journal of Medical Research. 2008 Jun 1;127(6):555-63.

10. Gupta R, Gupta N, Khedar RS. Smokeless tobacco and cardiovascular disease in low and middle income countries. Indian heart journal. $2013 \mathrm{Jul}$ 1;65(4):369-77.

11. Ramanan VV, Singh SK. A study on alcohol use and its related health and social problems in rural Puducherry, India. Journal of Family Medicine and Primary Care. 2016 Oct;5(4):804-808.
12. Bauman A, Bull F, Chey T, Craig CL, Ainsworth BE, Sallis JF, Bowles HR, Hagstromer M, Sjostrom M, Pratt M, IPS Group. The international prevalence study on physical activity: results from 20 countries. International journal of behavioral nutrition and physical activity. 2009 Dec $1 ; 6(1): 21$.

13. Shridhar K, Dhillon PK, Bowen L, Kinra S, Bharathi AV, Prabhakaran D, Reddy KS, Ebrahim $\mathrm{S}$, Indian Migration Study Group. The association between a vegetarian diet and cardiovascular disease (CVD) risk factors in India: the Indian Migration Study. PloS one. 2014 Oct 24;9(10):e110586.

14. Manchanda SC, Passi SJ. Selecting healthy edible oil in the Indian context. Indian heart journal. 2016 Jul;68(4):447.

15. Gupta R, Lodha S, Sharma KK, Sharma SK, Gupta S, Asirvatham AJ, Mahanta BN, Maheshwari A, Sharma DC, Meenawat AS, Khedar RS. Evaluation of statin prescriptions in type 2 diabetes: India Heart Watch-2. BMJ Open Diabetes Research and Care. 2016 Aug 1;4(1). 